$\mathbb{T}$ periodica polytechnica

Civil Engineering

$55 / 1(2011) 21+29$

doi: 10.3311/pp.ci.2011-1.03

web: http://www.pp.bme.hu/ci

(c) Periodica Polytechnica 2011

RESEARCH ARTICLE

\section{Cyclic behavior of a two-span RC beam built with plain reinforcing bars}

\author{
Catarina Fernandes / José Melo / Humberto Varum / Aníbal Costa
}

Received 2011-01-27, revised 2011-02-23, accepted 2011-03-09

\begin{abstract}
Reinforced concrete structural elements lacking appropriate seismic detailing and built with plain reinforcing bars, and subjected to cyclic loads like the ones induced by earthquakes, are particularly sensitive to the bond-slip mechanism. Though, existing studies on the cyclic behavior of RC structures generally refer to elements with deformed bars. As a result, the behavior of elements with plain bars is not yet fully understood. In this framework, the cyclic behavior of a two-span RC beam built with plain reinforcing bars, collected from an ancient building structure, was investigated. The support and loading conditions observed in-situ were simulated in the test setup. The beam displayed a flexural failure and the damage was concentrated in three short plastic hinges. The poor damage distribution evidences the effects of the bar slippage mechanism on the beam behavior.
\end{abstract}

\section{Keywords}

Existing RC structures; Plain reinforcing bars; Concretesteel bond; Cyclic test; Plastic hinges; Energy dissipation.

\section{Catarina Fernandes}

Civil Engineering Department, University of Aveiro, Campus Universitário de Santiago, Aveiro, 3810-193, Portugal

e-mail: cfernandes@ua.pt

\section{José Melo}

Civil Engineering Department, University of Aveiro, Campus Universitário de Santiago, Aveiro, 3810-193, Portugal

e-mail: josemelo@ua.pt

\section{Humberto Varum}

Civil Engineering Department, University of Aveiro, Campus Universitário de Santiago, Aveiro, 3810-193, Portugal

e-mail: hvarum@ua.pt

\section{Aníbal Costa}

Civil Engineering Department, University of Aveiro, Campus Universitário de Santiago, Aveiro, 3810-193, Portugal

e-mail: agc@ua.pt

\section{Introduction}

A significant number of existing reinforced concrete (RC) structures in Europe prior to the enforcement of the modern seismic-oriented design philosophies. In fact, many were designed to withstand only gravity loads. Also, they are generally reinforced with plain bars that exhibit poor bond and need specific anchoring end details [14]. As a consequence of poor reinforcement details and absence of any capacity design principles, a significant lack of ductility at both the local and global levels is expected for these structures resulting in inadequate structural performance even under moderate seismic excitation [17, 26]. Damages observed in recent severe earthquakes like, for example, the 2008 Sichuan-China, the 2009 L'Aquila-Italy, 2010 Port-au-Prince-Haiti and 2010 Chile earthquakes confirm the important source of risk that old RC structures represent the society, in both human and economic terms.

The common causes of damage and collapse of RC structures due to earthquakes are usually associated to the following effects/mechanisms [30]: (i) stirrups/hoops, confinement and ductility; (ii) bond, anchorage and lap-splices and bond splitting; (iii) inadequate shear capacity and failure; (iv) inadequate flexural capacity and failure; (v) inadequate shear strength of the joints; (vi) influence of the infill masonry on the seismic response of structures; (vii) vertical and horizontal irregularities; (viii) effect of higher modes; (ix) strong-beam weak-column mechanism; and, (x) structural deficiencies due to architectural requirements.

The sudden loss of concrete-steel bond is one of the sources of brittle failure in RC elements, and is reported to have been the cause of severe local damage and even collapse of many structures during earthquakes. Even if no anchorage failure occurs, the hysteretic behavior of RC structures, namely when subjected to alternate actions (like earthquakes), is highly dependent on the interaction between steel and concrete [6].

Perfect bond between the steel reinforcing bars and the surrounding concrete is usually assumed in the analyses of RC structures, implying full compatibility between concrete and steel strains. However, this assumption is only valid for early loading stages and low strain levels. As the loads increases, 
cracking and bond failure unavoidably occurs and relative slip between the concrete and the reinforcing bars (bond-slip) takes place in the structural elements. Consequently, different strains are observed in the steel bars and in the surrounding concrete, and the stress distribution is affected in both materials [30]. In RC structural elements subjected to cyclic loading the concretesteel bond can deteriorate even before the stress state has attained the yield stress of the steel and the stress strength of the concrete [3, 30]. RC elements built with plain reinforcing bars under cyclic loading are particularly sensitive to the bond-slip mechanism.

Existing studies on the cyclic behavior of RC structures and on bond behavior generally refer to elements with deformed bars. Although some experiments have been devoted to assess global performances of old-type structures, local aspects like the concrete-steel bond were not exhaustively investigated. Consequently, the influence of plain bars on the nonlinear response of isolated elements and critical regions (like beam-column joints) is not yet fully established [14].

In terms of experimental studies, many 50 years old and even older experimental results on plain bars can be found, but they are basically presented as reference data for deformed bars [14]. Recent experiments have been performed on RC structural elements with plain reinforcing bars. Examples can be found in Verderame et al. [31, 32] and Acun and Sucuoglu [2] (on columns), Liu and Park [20], Pampanin et al. [26] and Bedirhanoglu et al. [4] (on beam-column joints), and Varum [30] and Pinto et al. [27, 28] (on frame structures). Other experiments are particularly focused on the analysis of bond behavior (Fabbrocino et al. [15], Feldman and Bartlett [16], Xiao and Falkner [35], Verderame et al. [33, 34]).

If reports on the behavior of RC elements with plain reinforcing bars are limited, this is particularly evident when it comes to RC beams. Recent studies on the behavior of RC beams refer, in general, to elements built with deformed bars. For example: i) Kovács and Farkas [29] conducted a series of tests in laboratory on a lightly reinforced concrete beam, aiming to study the continuous monitoring of concrete bridges during their design life; ii) Draskóczy [12] tested a series of 24 reinforced concrete beams with the main objective of developing the variable strut inclination method used for shear design of RC beams by Eurocode 2; iii) Koris and Bódis [18] presented a method for the calculation of flexural resistance of pre-cast RC beams as a function of time and relative ambient humidity, with the objective of determining the decrease of load carrying capacity in time due to slow deformations and aging of materials and calculating the probability of failure of the structure by means of varying the load carrying capacity and external loads. Among the very scarce number of existing work about the cyclic behavior of beams built with plain bars, a recent work by Marefat $e t$ al. [22] can be referred as an example. In the work developed by the authors, three types of beam specimens were tested under alternate cyclic loading: (i) substandard specimens, with defi- cient seismic detailing and reinforced by plain bars; (ii) specimens designed in accordance with ACI318-99, but reinforced by plain bars; and, (iii) standard specimens reinforced by deformed bars. Among other conclusions, the tests showed that the substandard specimens sustained relatively large slip of longitudinal bars, limited lateral displacement capacity and loss of nominal yield strength. The standard specimens with plain bars and deformed bars presented a similar behavior, but larger slip and smaller yield strength was verified in the elements with plain bars.

In terms of analytical and numerical models for describing the concrete-steel bond behavior, the existing models that establish the bond stress-slip relationship, like the ones described in Ref. 5 , were mainly developed for specimens with deformed bars. The model adopted by CEB-FIP Model Code 90 [8] for describing the bond behavior of deformed bars is based on the bond stress-slip relationship proposed by Eligehausen et al. [13]. In order to adjust the model for plain reinforcing bars, CEB-217 [7] gives a proposal for the model parameters to be used in this situation. Recently, Verderame et al. [34] proposed a bond stressslip relationship and corresponding hysteretic rules, based on the results from monotonic and cyclic pullout test described in [33]. According to the authors, the analytical model proposed is able to represent the interaction mechanisms between plain reinforcing bars and the surrounding concrete, as confirmed in the confrontation with the experimental results.

Considerable research work has been developed with the objective of including the bond-slip effects in the analysis of RC elements. Reference to recent numerical work on this subject can be found in [19]. Among the available numerical tools for performing structural analysis, only a few (for example, CASTEM [24], OpenSees [25] and ATENA [11]) allow taking into account the bond-slip mechanism.

In this paper is described the cyclic test of a RC beam, collected from an ancient structure, built with plain reinforcing bars. The beam was subjected to unidirectional cyclic loads until collapse, considering symmetrical geometrical and loading conditions. The support and loading conditions observed in-situ were simulated in the test setup. The test set-up is described and the main experimental results are presented namely in terms of force-deflection diagrams, deformed shape and damage evolution, energy dissipation and beam rotation at supports. The beam displayed a flexural failure and the damage was concentrated in three short plastic hinges. The poor damage distribution evidences the effects of the bar slippage mechanism on the beam behavior. The experimental results will contribute to enlarge the existing database on the cyclic behavior of RC elements with plain reinforcing bars. Also, the results obtained with this test will allow to upgrade and calibrate numerical models for the adequate simulation of the cyclic behavior of this type of elements (see [23]). 


$\begin{array}{cccc}\begin{array}{c}\text { left } \\ \text { support }\end{array} & \begin{array}{c}\text { middle } \\ \text { support }\end{array} & \text { right span } \\ & 4.0 \mathrm{~m} & 4.0 \mathrm{~m} & \begin{array}{c}\text { right } \\ \text { support }\end{array}\end{array}$

(a)

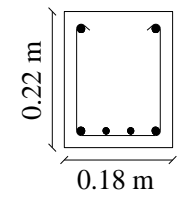

(b)

Fig. 1. Geometrical characteristics of the RC beam: a) identification of spans and support conditions; b) cross-section.

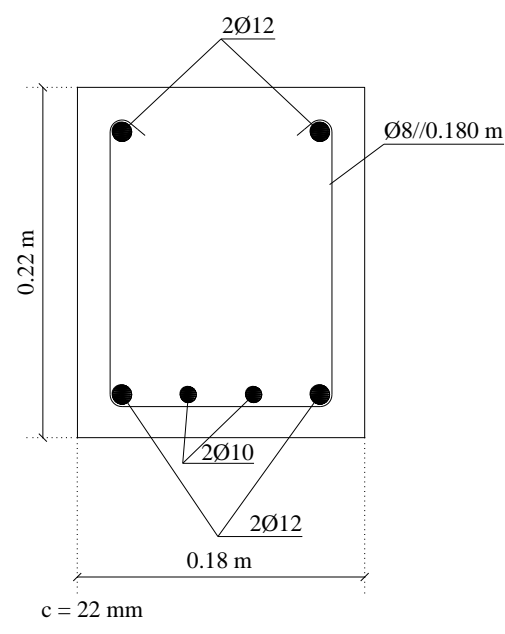

(a)

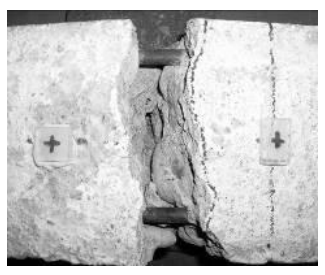

b)

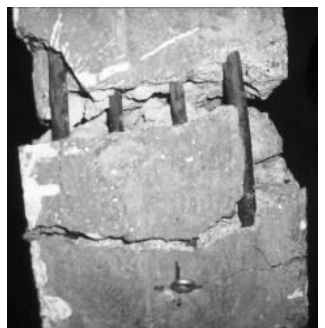

c)

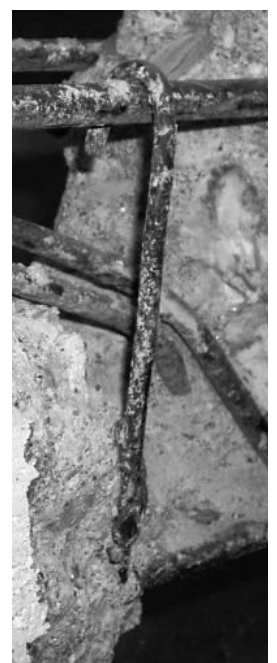

(d)

Fig. 2. Steel reinforcement: a) beam cross-section; b) top longitudinal steel bars; c) bottom longitudinal steel bars; d) U-stirrups.

\section{Cyclic Test of a RC Beam built with Plain Reinforcing Bars}

This section addresses the cyclic test of a RC beam built with plain reinforcing bars, that was collected from the Santa Joana Museum (an aggregate of ancient constructions, part of the cultural and historical heritage of the city of Aveiro, in Portugal), in 2007, during the partial demolition of one its buildings. Materials properties, test set-up and main experimental results are presented and discussed. At the existing building, the two-span beam was part of the roof's support structure and was loaded by one vertical element at each middle-span section. The support and loading conditions observed in-situ were simulated in the test setup.

\subsection{General geometrical characteristics and support condi-} tions

The RC beam is characterized by a rectangular $0.18 \times 0.22 \mathrm{~m}^{2}$ cross-section (Fig. 1 a) and a total span of $8 \mathrm{~m}$. The beam support conditions considered for the experimental test are illustrated in Fig. 1 b.

\subsection{Materials}

\subsubsection{Concrete}

No information about the concrete mechanical properties was available. In order to estimate the concrete's compressive strength, four cylindrical concrete samples were extracted from the beam after the test and subjected to compression testing. According to the ASTM C42/C42M standard [1], if the length-to- diameter ratio of the sample is between 1.75 and 1.00, the corresponding concrete strength must be multiplied by a correction factor. Thus, the strength values computed for each concrete sample were multiplied by the appropriate correction factor. A mean strength $\left(f_{\mathrm{cm}}\right)$ equal to $19 \mathrm{MPa}$ and standard deviation $(\Delta)$ equal to 1.32 were obtained. The characteristic compressive strength $\left(f_{c k}\right)$ estimated is equal to $16.8 \mathrm{MPa}$. According to the Eurocode 2 (EC2 [9]) classification, the concrete class is C16/20.

Concrete grade limitations are presented by Eurocode 8 (EC8 [10]) for primary seismic elements considering different ductility classes. Structures with low capacity to dissipate energy belong to the low ductility class. Medium and high ductility classes (DCM and DCH, respectively) correspond to structures designed, dimensioned and detailed according to specific earthquake resistant provisions. According to EC8, for DCM and DCH structures, a concrete class lower than C16/20 and C20/25, respectively, shall not be used. This requirement is fulfilled by the beam under study only for DCM structures.

\subsubsection{Steel reinforcement}

No information was available about the steel mechanical properties and reinforcing bars detailing and since it was not possible to obtain steel bars samples, tensile strength tests were not performed. From the observations made at the museum, only plain reinforcing bars were used in the construction of the beam. Measurements made with a rebar detector before the experimental test and the posterior demolition of the beam, allowed identi- 
fying the number, diameter and position of the reinforcing bars (Fig. 2).

Regarding the longitudinal steel reinforcement: (i) the number, diameter and position of the reinforcing bars is constant along the beam span; (ii) the bottom reinforcement is constituted by two bars of $10 \mathrm{~mm}$ diameter and two bars of $12 \mathrm{~mm}$ diameter, corresponding to a cross-sectional area $\left(A_{s l, b o t}\right)$ and longitudinal reinforcement ratio $\left(\rho_{l, b o t}\right)$ equal to $3.83 \mathrm{~cm}^{2}$ and $1.16 \%$, respectively; (iii) the top reinforcement is constituted by two bars of $12 \mathrm{~mm}$ diameter, corresponding to a cross-sectional area $\left(A_{s l, t o p}\right)$ and reinforcement ratio $\left(\rho_{l, t o p}\right)$ equal to $2.26 \mathrm{~cm}^{2}$ and $0.68 \%$, respectively; (iv) the total area of longitudinal reinforcement $\left(A_{s l}\right)$ and total longitudinal reinforcement ratio $\left(\rho_{l}\right)$ are equal to $6.09 \mathrm{~cm}^{2}$ and $1.84 \%$, respectively; (v) the mean distance between bottom bars $\left(s_{l, b o t}\right)$ is equal to $25.33 \mathrm{~mm}$ and the distance between top bars $\left(s_{l, t o p}\right)$ is equal to $96 \mathrm{~mm}$.

Regarding the shear reinforcement: (i) is constituted by Ushaped $8 \mathrm{~mm}$ diameter stirrups; (ii) the shear reinforcement ratio $\left(\rho_{w}\right)$ is equal to $0.31 \%$; (iii) the cross-sectional area-distance between stirrups ratio $\left(A_{s w} / s_{w}\right)$ is equal to $5.59 \mathrm{~cm}^{2} / \mathrm{m}$; (iv) the longitudinal distance between stirrups $\left(s_{w}\right)$ is roughly constant along the beam span and equal to $180 \mathrm{~mm}$; (v) the angle $(\alpha)$ between the stirrups and the longitudinal reinforcing bars is equal to $90^{\circ}$. The use of U-stirrups as transverse reinforcement reflects the lack of concern of old design standards regarding the importance of concrete confinement. Referring to the design practice at the time in which the beam was constructed, transverse reinforcement was designed only for shear resistance purposes.

The mean value registered for the concrete cover $(c)$ is equal to $22 \mathrm{~mm}$.

The values recommended by EC2 [9] and EC8 [10] for the main parameters of the steel reinforcement detailing in $\mathrm{RC}$ beams were estimated and are presented in Tab. 11. where: (i) $A_{s, \min }$ is the minimum cross-sectional area of the longitudinal reinforcement in the tension zone (within the critical regions of the beam, for EC8); (ii) $A_{s, \max }$ is the maximum cross-sectional area of longitudinal reinforcement (either in the tension or the compression zones); (iii) $\rho_{\min }$ is the minimum longitudinal reinforcement ratio of the tension zone; (iv) $\rho_{\max }$ is the maximum longitudinal reinforcement ratio of the tension zone within the critical regions of the beam; (v) $s_{\min }$ is the minimum distance between longitudinal reinforcing bars; (vi) $\rho_{w, \min }$ is the minimum shear reinforcement ratio; (vii) $s_{w, \max }$ is the maximum longitudinal spacing between shear reinforcing bars; (viii) $s_{w, \text { max }, \text { crit }}$ is the maximum longitudinal spacing between shear reinforcing bars within the critical regions of the beam; and, (ix) $d_{b w}$ is the minimum hoop diameter. A medium ductility class (DCM) was considered for calculating the EC8 values.

The computation of the EC2 and EC8 values was made considering the cross-section geometrical characteristics and materials properties shown in Tab. 2 where: (i) $b, h$ and $d$ are the cross-section width, depth and effective depth, respectively; (ii) $A_{c}$ is the concrete cross-sectional area; (iii) $f_{c}$ and $f_{c t}$ are
Tab. 1. Recommendations by EC2 [9] and EC8 [10] for the steel reinforcement in RC beams.

\begin{tabular}{ccccc}
\hline & \multicolumn{2}{l}{ Longitudinal reinforcement } & \multicolumn{2}{l}{ Shear reinforcement } \\
\hline \multirow{2}{*}{ EC2 } & $A_{s, \min }\left(\mathrm{cm}^{2}\right)$ & 0.43 & $\rho_{w, \min }(\%)$ & 0.14 \\
\cline { 2 - 5 } & $A_{s, \max }\left(\mathrm{cm}^{2}\right)$ & 15.60 & $s_{w, \max }(\mathrm{mm})$ & 138 \\
\cline { 2 - 5 } & $s_{\min }(\mathrm{mm})$ & 30 & & \\
\hline EC8 & $A_{s, \min }\left(\mathrm{cm}^{2}\right)$ & 1.92 & $d_{b w}(\mathrm{~mm})$ & 6 \\
\cline { 2 - 5 } & $\rho_{\min }(\%)$ & 0.36 & $\rho_{w, \min }(\%)$ & 0.14 \\
\cline { 2 - 5 } & $\rho_{\max }(\%)$ & 2.48 & $s_{w, \max }(\mathrm{mm})$ & 138 \\
\hline & & $s_{w, \max , \text { crit }}(\mathrm{mm})$ & 55 \\
\hline
\end{tabular}

the concrete compressive strength and tensile strength, respectively; (iv) $f_{y}$ and $\varepsilon_{s y}$ are the steel reinforcement yield strength and steel strain at yield, respectively; and, (v) $\mu_{\Phi}$ is the curvature ductility factor. Mean values were considered for the materials properties. The concrete compressive strength corresponds to the mean strength obtained in the compression tests. The concrete tensile strength is between the tensile strength of the C12/15 and C16/20 concrete classes. The S235 steel class was considered, given its very common use in old RC building structures.

Tab. 2. Parameters adopted for the computation of the EC2 [9] and EC8 [10] values in Tab. 1

\begin{tabular}{ccc}
\hline \multicolumn{2}{c}{ Parameter } & Value \\
\hline \multirow{3}{*}{ Cross-section } & \multicolumn{1}{c}{$b(\mathrm{~mm})$} & 180 \\
\cline { 2 - 3 } & $h(\mathrm{~mm})$ & 220 \\
\cline { 2 - 3 } & $d(\mathrm{~mm})$ & 184 \\
\cline { 2 - 3 } Materials properties & $A_{c}\left(\mathrm{~cm}^{2}\right)$ & 396 \\
\cline { 2 - 3 } & $f_{c t}(\mathrm{MPa})$ & 17 \\
\cline { 2 - 3 } & $f_{y}(\mathrm{MPa})$ & 1.7 \\
\cline { 2 - 3 } & $\varepsilon_{s y}(\%)$ & 0.12 \\
\hline Ductility factor & $\mu_{\Phi}$ & 6.2 \\
\hline
\end{tabular}

From the comparison between the values estimated for the beam under study and the values computed according to EC2, the following conclusions can be drawn: (i) the amounts of longitudinal and shear reinforcement are in accordance with the EC2 rules; (ii) the requirement concerning the minimum distance between longitudinal bars is verified only in the case of the top bars; and, (iii) the requirement concerning the maximum longitudinal spacing between the shear reinforcing bars is not met.

From the comparison with the EC8 values: (i) outside critical regions, the longitudinal and shear reinforcement ratios requirements are fulfilled, but not the maximum longitudinal spacing between the shear reinforcing bars; (ii) within the critical re- 

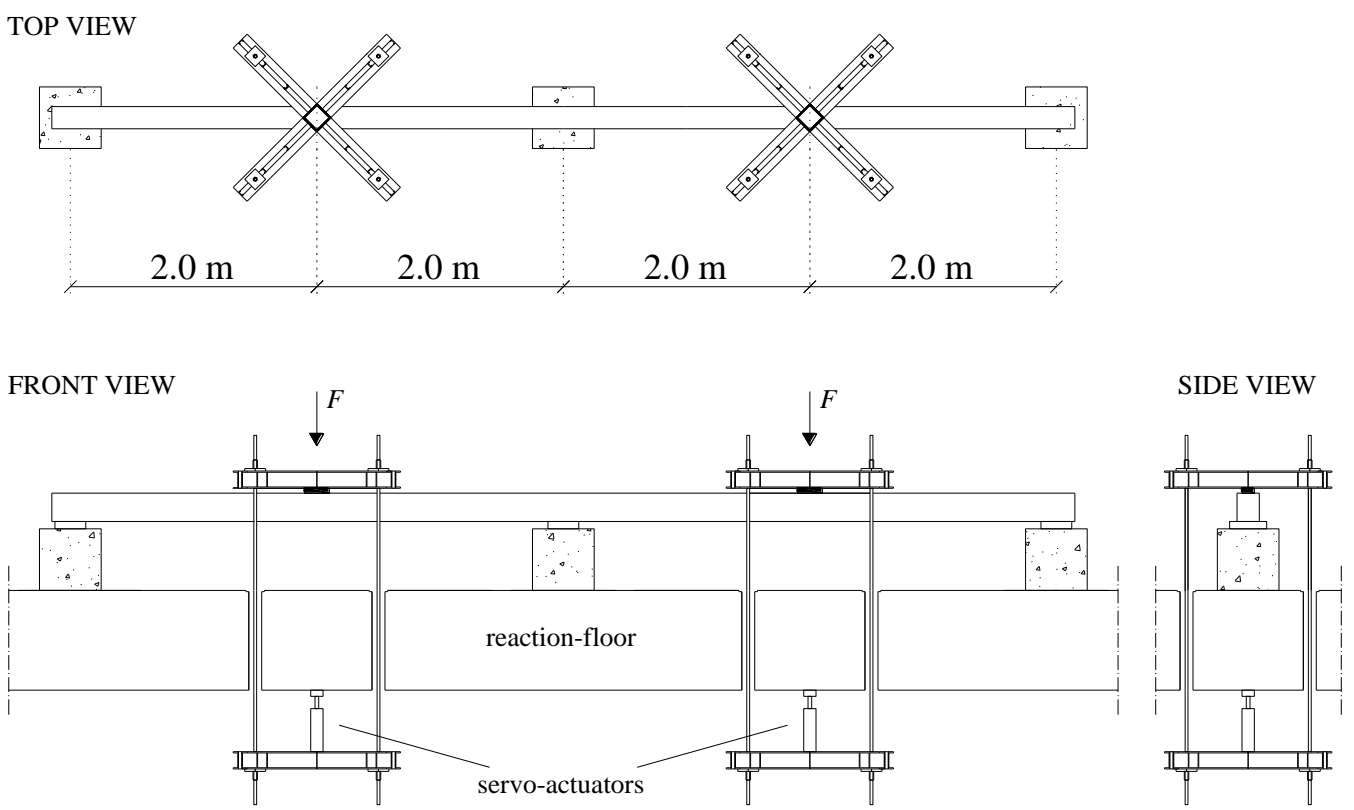

Fig. 3. Test set-up.

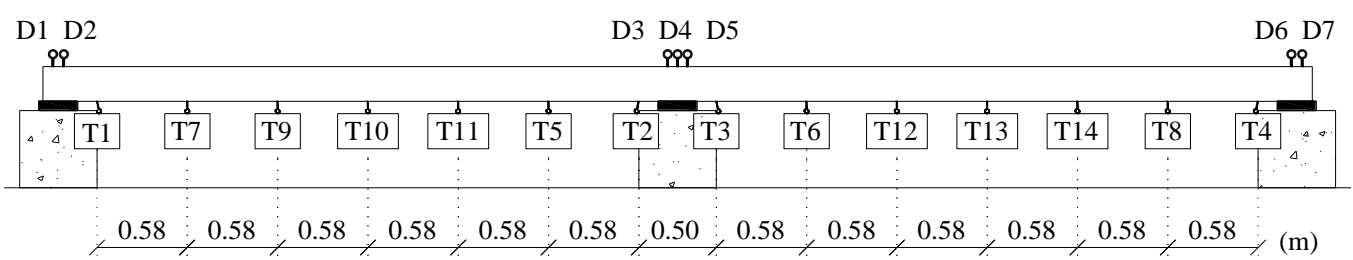

$\mathrm{T}$ - displacement transducer

D - dial indicator

Fig. 4. Location of displacement transducers and dial indicators.

gions, the minimum amount of longitudinal reinforcement is in accordance with the requirements, the maximum ratio of longitudinal reinforcement is exceeded and the requirement about the maximum longitudinal spacing between shear reinforcing bars is not satisfied. Also, with exception of closed stirrups and cross-ties, EC8 only allows the use of ribbed bars as reinforcing steel in critical regions of primary seismic elements. In the beam under study only plain reinforcing bars are present.

\subsection{Test set-up}

\subsubsection{Loading system}

In Fig. 3 is illustrated the test set-up adopted for the experimental test. Two hydraulic servo-actuators were placed bellow the reaction-floor for inducing the vertical forces $(F)$ at the midspan sections of the beam's left and right spans (left mid-span and right mid-span, respectively) The transmission of loads from the servo-actuators to the beam was made resorting to four Xshaped steel elements, two at the top of the beam and two underneath the reaction-floor. The top steel elements were connected to the bottom elements by $20 \mathrm{~mm}$ threaded steel bars. The tensioning of the steel bars allowed the transmission of loads to the beam.

\subsubsection{Instrumentation}

The monitoring of vertical displacements was made resorting to draw wire displacement transducers. For evaluating the beam rotation at the left, right and middle support sections, dial indicators were used. In Fig. 4 is illustrated the location of the displacement transducers and dial indicators. Transducers placed at the left and right mid-span sections were used to monitor the deflection of each span. The remaining transducers were placed for capturing the deformed shape of the beam.

\subsubsection{Loading history}

The beam was loaded by two vertical forces $(F)$, symmetrically positioned at the left and right mid-span sections, according to the loading history shown in Fig. 5. The cyclic test was made under force-controlled conditions. The forces are always descending describing series of three loading-unloading cycles of increasing amplitude, until a maximum force of $25 \mathrm{kN}$, when it was observed the beam collapse. The self-weight of the beam, which is roughly equal to $1 / 4-1 / 3$ of the maximum load achieved, is not considered in Fig. 5 . 


\subsection{Experimental results}

\subsubsection{Deflections evolution}

In Fig. 6 is shown the evolution of the left and right spans deflection ( $d_{l}$ and $d_{r}$, respectively), recorded by the transducers located at the left and right mid-span sections. A similar deflection is displayed by the two spans approximately for the first four load amplitudes. Then, the left span deflection begins to increase with higher rate. The maximum deflection registered for the left and right spans is equal to $0.12 \mathrm{~m}$ and $0.03 \mathrm{~m}$ (about $25 \%$ of the left span deflection), respectively.

\subsubsection{Force-deflection diagrams}

In Fig. 7 are shown the force-deflection diagrams plotted for the left and right mid-span sections. As it can be observed, the two spans show similar stiffness but a slightly higher resistant capacity is displayed by the right span.

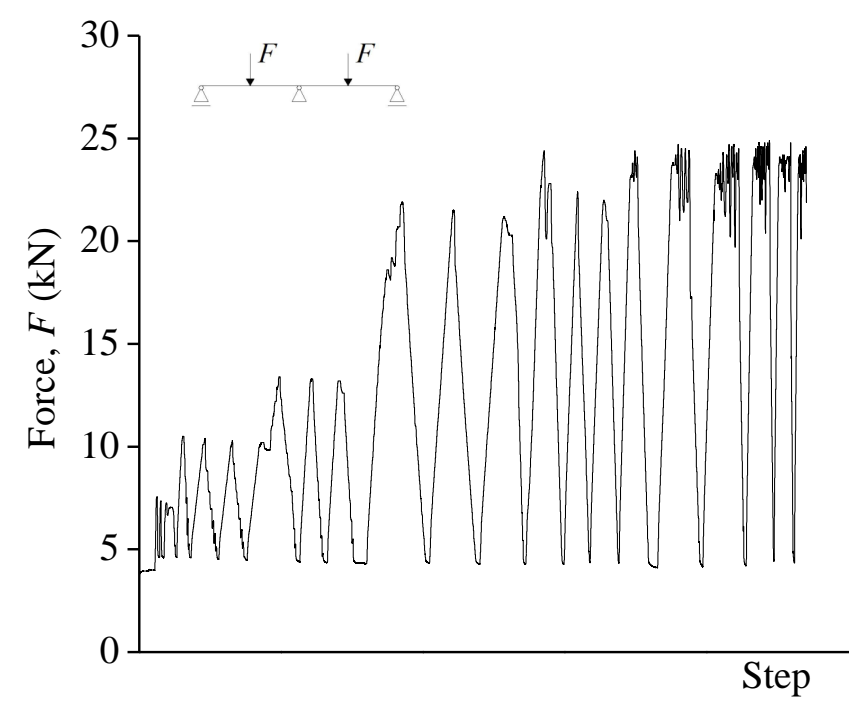

Fig. 5. Loading history.

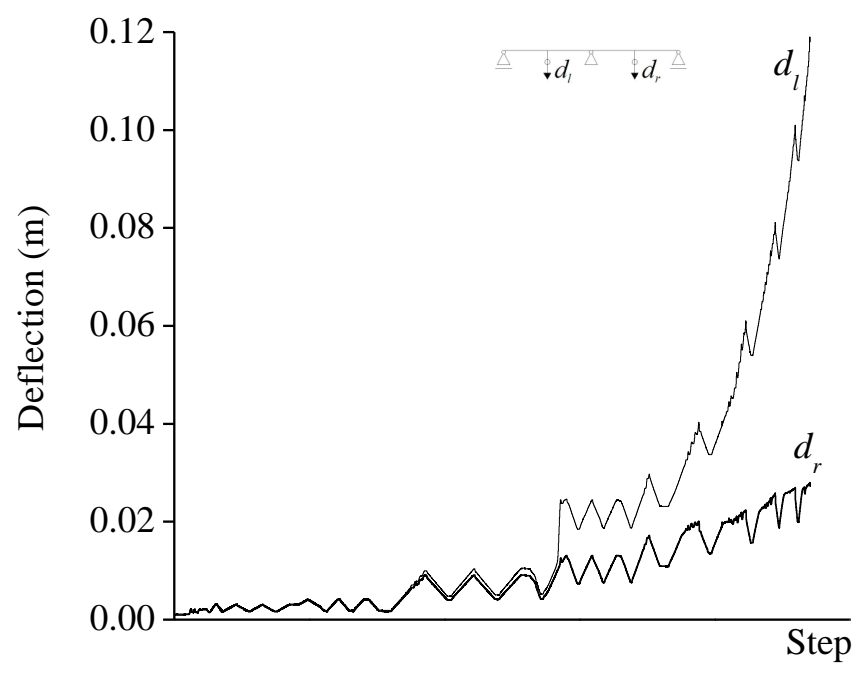

Fig. 6. Deflections evolution.

\subsubsection{Evolution of damages and deformed shape}

In Fig. 8 is shown the location of the three plastic hinges formed during the test, with indication of the corresponding

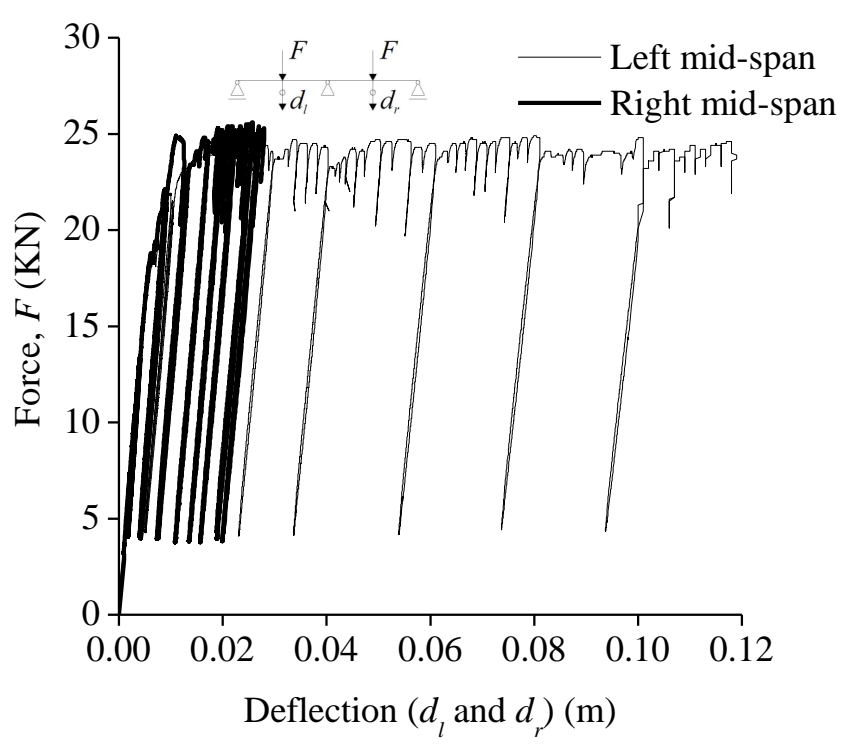

Fig. 7. Force-deflection diagrams.

length and occurrence sequence. The first hinge $\left(\mathrm{PH}_{1}\right)$ was developed at the middle support, the second hinge $\left(\mathrm{PH}_{2}\right)$ at the left mid-span section, and the third hinge $\left(\mathrm{PH}_{3}\right)$ at the right mid-span section. The length estimated for each hinge, corresponding to the length of the zone with more significant damage, is equal to: $0.05 \mathrm{~m}$ for $\mathrm{PH}_{1}, 0.14 \mathrm{~m}$ for $\mathrm{PH}_{2}$ and $0.15 \mathrm{~m}$ for $\mathrm{PH}_{3}$.

The observed crack pattern suggests that flexural failure occurred. Cracks were concentrated around the plastic hinges region, what can be considered evidence of the occurrence of slippage between the longitudinal reinforcing bars and the surrounding concrete. Bond-slip affects the stress transference between the two materials and, consequently, the crack propagation. Cracks do not spread along the element's span. Instead, their width increases significantly during the test. As a consequence, poor bond influences also the length of the plastic hinges by reducing its value.

The use of large dimension aggregates in the concrete composition intensified the severe concrete crushing observed at the plastic hinges location.

The general evolution of the beam deformed shape is illustrated in Fig. 9. The deformed shape of the beam remains roughly symmetrical until the development of cracks at the two mid-span sections.

\subsubsection{Failure mode}

Based only on the crack pattern observed, the occurrence of flexural failure is suggested. To verify that shear failure did not occur, the beam shear strength was computed and compared with the estimated value for the maximum shear achieved in the experimental test.

In Fig. 10 are shown the shear and bending moment diagrams corresponding to the maximum load registered in the test (equal to $25 \mathrm{kN}$ ), computed considering a linear elastic analysis. The maximum values estimated for the shear and bending moment are equal to $17 \mathrm{kN}$ and $17 \mathrm{kNm}$, respectively. Since the com- 


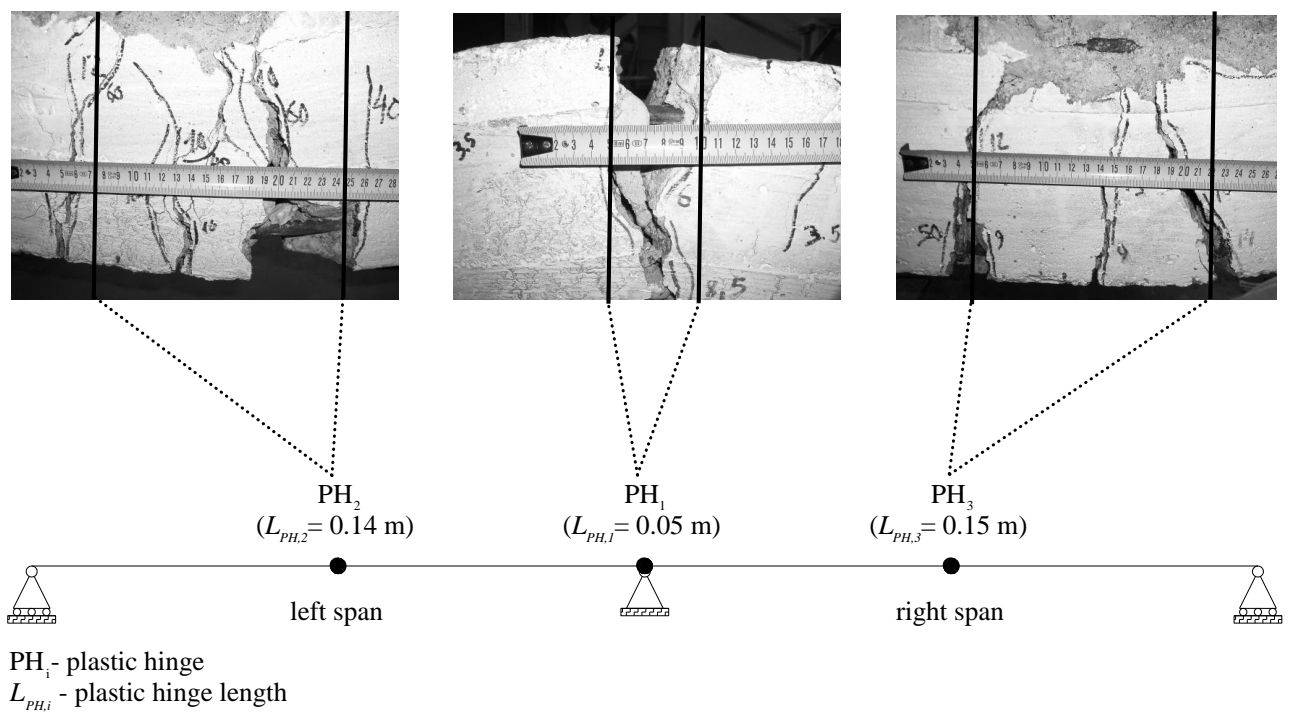

Fig. 8. Plastic hinges location and length.

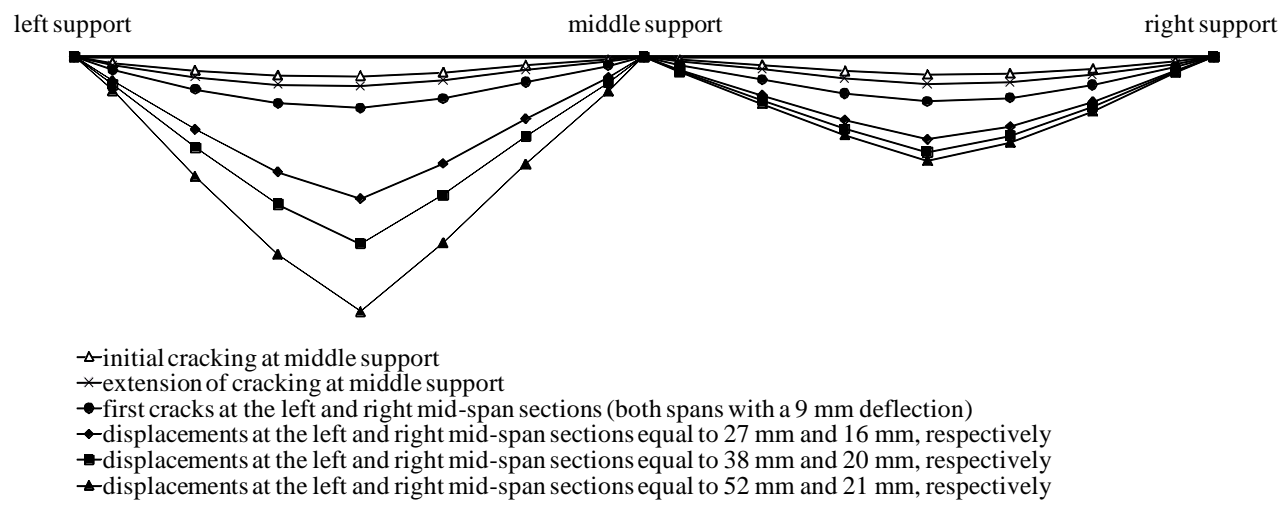

Fig. 9. Evolution of the beam deformed shape.

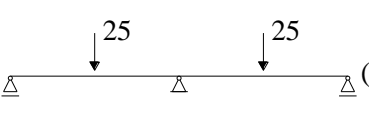

(a)

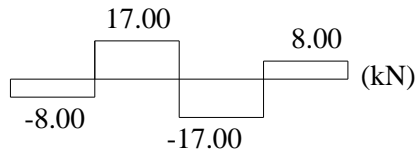

(b)

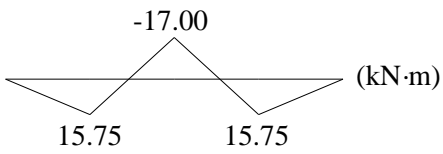

(c)

Fig. 10. Maximum acting loads: a) loads; b) shear diagram; c) bending moment diagram.

putation was made considering a linear elastic behavior, these values do not correspond to the real maximum shear and bending moment of the beam. Though, they can be used to estimate the beginning of cracking and to calculate an upper-bound limit of the shear in the beam, confirming that the shear resistance is not exceeded during the test.

The shear resistance was computed according to EC2 [9] considering the materials properties shown in Tab. 2 The shear strength was computed taking into account the shear reinforcement present in the beam, and it was estimated a value equal to $61.3 \mathrm{kN}$. Since this value is superior to the estimated maximum shear $(17 \mathrm{kN})$, shear failure did not occur.

\subsubsection{Energy dissipation evolution}

In Fig. 11 is shown the energy dissipation evolution computed from the experimental results.

\subsubsection{Evolution of the beam rotation at supports}

From readings of the dial indicators made during the experimental test for different load amplitudes, it was estimated the beam rotation at the two external supports. The rotation at the middle support was not estimated since the (D3, D4 and D5) dial indicators readings were affected by the development of plastic hinge $\mathrm{PH}_{1}$. Since very small bending deformations were expected at the two external supports, confirmed by the absence of damage observed at these points, the corresponding support rotations were computed considering the beam extent instrumented as a rigid body. The loading force-rotation (absolute 


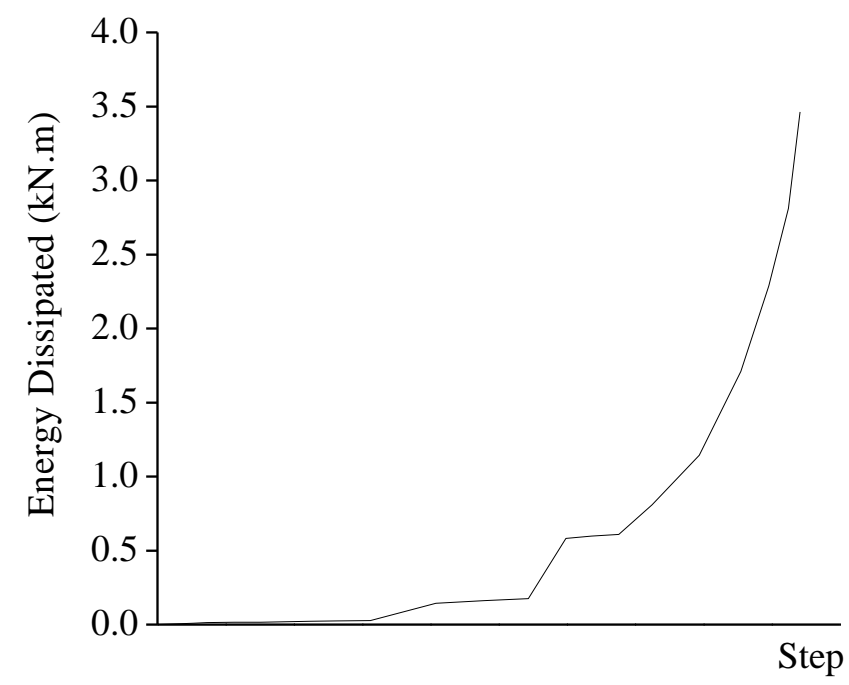

Fig. 11. Evolution of the total energy dissipated by the beam.

values) relationships are displayed in Fig. 12 Rotations at the two supports were initially very similar until significant differences between the left and right mid-span displacements began to be observed. The estimated values for the maximum rotation at the left and right supports $\left(\theta_{l}\right.$ and $\theta_{r}$, respectively) are equal to $0.018 \mathrm{rad}$ and $0.011 \mathrm{rad}$, respectively. The maximum rotation at the right support is about $62 \%$ of the maximum rotation at the left support.

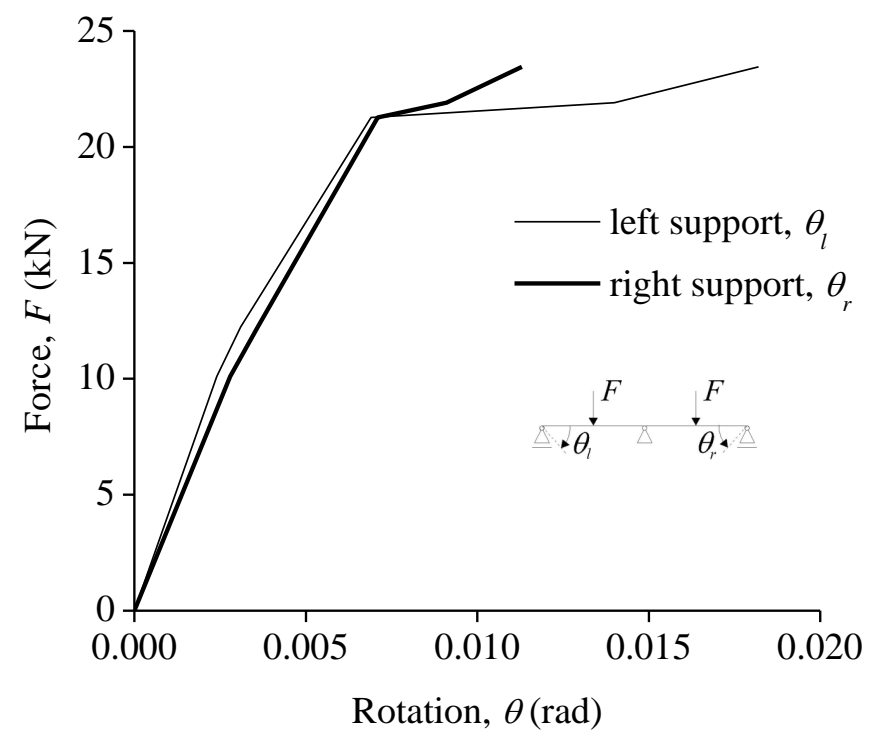

Fig. 12. Imposed force versus rotation (absolute values) diagrams for the left and right supports.

\section{Conclusions}

The behavior of a two-span RC beam built with plain reinforcing bars, collected from an ancient building structure, and subjected to unidirectional cyclic loads, was investigated. Symmetrical geometrical and loading conditions were considered in the experimental test.

Compression tests of cylindrical concrete samples, extracted from the beam after the experimental test, were made to esti- mate the concrete strength. The results indicate that the concrete class is $\mathrm{C} 16 / 20$ according to the EC2 classification. The beam reinforcement detailing was compared with the requirements given by EC2 and EC8. The EC2 requirements are not fulfilled in terms of minimum distance between the longitudinal bottom bars and maximum spacing between the shear reinforcing elements. The EC8 requirements are not fulfilled in terms of maximum spacing between the shear reinforcing elements, both outside and within the critical regions, as well as in terms of maximum longitudinal reinforcement ratio the critical regions. The use of plain reinforcing bars and the concrete class are not also in accordance with the EC8 requirements.

The beam displayed a flexural failure and three short plastic hinges were developed. Cracks were concentrated in the plastic hinges, evidencing the occurrence of slippage between the reinforcing bars and the surrounding concrete.

Although similar stiffness was displayed by the two spans, higher resistant capacity was shown by the right span. The left span exhibited higher deflection. Maximum deflection of the right span was estimated to be $25 \%$ of the one registered for the left span. The maximum rotation at the right support of the beam was estimated to be about $62 \%$ of the corresponding for the left support. Non-perfect symmetry of the beam in terms of span length, materials properties or reinforcement detailing, justifies the differences experimentally observed between the global behavior of the two spans, namely in terms of damage evolution, deflection, rotation and collapse moment.

The influence of the plain bar slippage in the global response of the tested beam proves to be a key factor. Therefore, for a precise performance assessment of existing RC building structures, the bond-slip mechanism cannot be disregarded. The results obtained with this test will allow to upgrade and calibrate numerical models for the adequate simulation of the cyclic behavior of existing RC structures built with plain reinforcing bars.

\section{Acknowledgement}

This paper reports research developed under financial support provided by "FCT - Fundação para a Ciência e Tecnologia", Portugal, namely through the $\mathrm{PhD}$ grants of the first and second authors, with references SFRH/BD/27406/2006 and SFRH/BD/62110/2009, respectively. The authors would like to acknowledge: (i) Prof. António Arêde, Eng. Alexandre Costa, Mr. Valdemar Luís and Mr. André Martins, from the Laboratory of Seismic and Structural Engineering of the Faculty of Engineering of the University of Porto (LESE-FEUP, Portugal) for their collaboration in the execution of the tests; (ii) Eng. Hugo Rodrigues, Eng. Romeu Vicente, Eng. Henrique Pereira and Eng. Elsa Neto, from the Civil Engineering Department of the University of Aveiro (Portugal), for their collaboration; (iii) Civilria Construções, Silva Tavares \& Bastos Almeida, Lda. and Arlindo Correia \& Filhos S.A. for the help in the construction of the test set-up; and, (iv) the Santa Joana Museum, Aveiro, for giving access to the building where the beam specimen was collected. 


\section{References}

1 ASTM C42/C42M - Standard Test Method for Obtaining and Testing Drilled Cores and Sawed Beams of Concrete, American Association of State Highway and Transportation Officials, 1999.

2 Acun B, Sucuoglu H, Performance of reinforced concrete columns designed for flexure under severe displacement cycles, ACI Structural Journal 107 (2010), no. 3, 364-371.

3 Berra M, Castellani A, Ciccotelli S, Coronelli D, Bond-slip effects on reinforced concrete elements under earthquake loading, European Earthquake Engineering 3 (1994), 3-10.

4 Bedirhanoglu I, Ilki A, Pujol S, Kumbasar N, Behavior of deficient joints with plain bars and low-strength concrete, ACI Structural Journal 107 (2010), no. 3, 300-310.

5 Bigaj A J, Structural dependence of rotation capacity of plastic hinges in $R C$ beams and slabs, PhD thesis, Delft University of Technology, The Netherlands, 1999.

6 Comité Euro-International du Béton, RC elements under cyclic loading. State of the-art report, Thomas Telford Publications, London, 1996.

7 CEB-217 - Bulletin d'Information N. 217 - Selected justification notes, Comité Euro-International du Béton, Lausanne, Switzerland, 1993

8 CEB-FIP Model Code 90, Comité Euro-International du Béton, Lausanne, Switzerland, 1990.

9 EN 1992-1-1:2004. Eurocode 2: Design of concrete structures - Part 1-1: General rules and rules for buildings, European Committee for Standardization, Brussels, Belgium, 2004.

10 EN 1998-1:2004. Eurocode 8: Design of structures for earthquake resistance - Part 1: General rules, seismic actions and rules for buildings, European Committee for Standardization, Brussels, Belgium, 2004.

11 Cervenka J, Jendele L, Atena user's manual, Part 1-7, Cervenka Consulting Ltd., Prague, Czech Republic, Unknown Month 2000.

12 Draskóczy A, Shear tests evaluation and numerical modelling of shear behaviour of reinforced concrete beams, Periodica Polytechnica Architecture 40 (2009), no. 1, 9-17.

13 Eligehausen R, Popov E P, Bertero V V, Local bond stress-slip relationships of deformed bars under generalized excitation, Earthquake Engineering Research Center, University of California, 1983.

14 Fabbrocino G, Verderame G, Manfredi G, Cosenza E, Structural models of critical regions in old-type R.C. frames with smooth rebars, Engineering Structures 26 (2004), no. 14, 2137-2148.

15 Fabbrocino G, Verderame G, Manfredi G, Experimental behavior of anchored smooth rebars in old type reinforced concrete buildings, Engineering Structures 27 (2005), no. 10, 1575-1585.

16 Feldman L R, Bartlett F M, Bond strength variability in pullout specimens with plain reinforcement, ACI Structural Journal 102 (2005), no. 6, 860-867.

17 Hertanto E, Seismic assessment of pre-1970s reinforced concrete structures, PhD thesis, University of Canterbury, Christchurch, New Zealand, 2005.

18 Koris K, Bódi I, Long-term analysis of bending moment resistant on pre-cast concrete beams, Periodica Polytechnica Civil Engineering 53 (2009), no. 2, 53-60.

19 Limkatanyu S, Spacone E, Reinforced concrete frame element with bond interfaces. I: Displacement-based, force-based and mixed formulation, Journal of Structural Engineering 128 (2002), no. 3, 346-355.

20 Liu A, Park R, Seismic behaviour and retrofit of pre-1970's as-built exterior beam-column joints reinforced by plain round bars, Bulletin of the New Zealand Society for Earthquake Engineering 34 (2001), no. 1, 68-81.

21 Manfredi G, Pecce M, Behavior of bond between concrete and steel in a large post-yielding field, Materials and Structures 29 (1996), no. 8, 506-513.

22 Marefat M S, Shirazi S H M, Rostamshirazi R, Khanmohammadi M, Cyclic Response of Concrete Beams Reinforced by Plain Bars, Journal of Earthquake Engineering 13 (2009), no. 4, 463-481.

23 Melo J, Fernandes C, Varum H, Rodrigues H, Costa A, Arêde A, Nu- merical modelling of the cyclic behaviour of RC elements built with plain reinforcing bars, Engineering Structures 33 (2011), no. 2, 273-286.

24 Millard A, CASTEM 2000 - Guide d'utilisation, Saclay, France, 1993.

25 OpenSees - Open System for Earthquake Engineering Simulation. available online at http://opensees.berkeley.edu/index.php.

26 Pampanin S, Calvi S, Moratti M, Seismic behavior of RC beam-column joints designed for gravity loads, 12th European Conference on Earthquake Engineering (London, England, September 2002). Paper No. 726.

27 Pinto A V, Verzeletti G, Molina J, Varum H, Pinho R, Coelho E, Pseudodynamic tests on non-seismic resisting $R C$ frames (bare and selective retrofit frames), European Laboratory for Structural Assessment, Joint Research Centre, European Commission, 1999.

28 Pinto A V, Varum H, Molina J, Experimental assessment and retrofit of full-scale models of existing RC frames, 12th European Conference on Earthquake Engineering (London, England, September 2002). Paper No. 855.

29 Rákóczy K, Deák G, Analysis of continuous reinforced concrete beams in serviceability limit state, Periodica Polytechnica Architecture 38 (2007), no. 1, 11-16.

30 Varum H, Seismic assessment, strengthening and repair of existing buildings, $\mathrm{PhD}$ thesis, University of Aveiro, Aveiro, Portugal, 2003.

31 Verderame G M, Fabbrocino G, Manfredi G, Seismic response of R.C. columns with smooth reinforcement. Part I: Monotonic tests, Engineering Structures 30 (2008), no. 9, 2277-2288.

32 , Seismic response of R.C. columns with smooth reinforcement. Part II: Cyclic tests, Engineering Structures 30 (2008), no. 9, 2289-2300.

33 Verderame G M, Ricci P, De Carlo G, Manfredi G, Cyclic bond behavior of plain bars. Part I: Experimental investigation, Construction and Building Materials 23 (2009), no. 12, 3499-3511.

$34 \ldots$, Cyclic bond behavior of plain bars. Part II: Analytical investigation, Construction and Building Materials 23 (2009), no. 12, 3512-3522.

35 Xiao J, Falkner $\mathbf{H}$, Bond behavior between recycled aggregate concrete and steel rebars, Construction and Building Materials 21 (2005), no. 2, 395-401. 